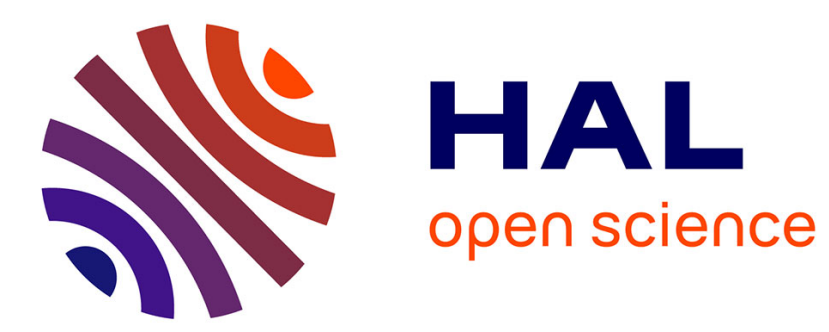

\title{
FLUX-FLOW VOLTAGE PULSES I N SUPERCONDUCTORS
}

\author{
J. Clem
}

\section{To cite this version:}

J. Clem. FLUX-FLOW VOLTAGE PULSES I N SUPERCONDUCTORS. Journal de Physique Colloques, 1978, 39 (C6), pp.C6-619-C6-620. 10.1051/jphyscol:19786278 . jpa-00217717

\section{HAL Id: jpa-00217717 https://hal.science/jpa-00217717}

Submitted on 1 Jan 1978

HAL is a multi-disciplinary open access archive for the deposit and dissemination of scientific research documents, whether they are published or not. The documents may come from teaching and research institutions in France or abroad, or from public or private research centers.
L'archive ouverte pluridisciplinaire HAL, est destinée au dépôt et à la diffusion de documents scientifiques de niveau recherche, publiés ou non, émanant des établissements d'enseignement et de recherche français ou étrangers, des laboratoires publics ou privés. 


\title{
FLUX-FLOW VOLTAGE PULSES IN SUPERCONDUCTORS
}

\author{
J.R. Clem, \\ Ames Laboratory-USDOE and Department of Physics, Iowa State University, Ames, Iowa 50011, U.S.A.
}

\begin{abstract}
Résumé.- On présente une nouvelle méthode de calcul de 1'impulsion de tension produite par le mouvement $d^{\prime}$ un vortex ou tube de flux.
\end{abstract}

Abstract.- A new theoretical method for the calculation of the measured voltage pulse produced by a moving flux vortex or flux tube is described.

INTRODUCTION. - A fundamental question of continuing interest is that of the origin of the measured voltage $\mathrm{V}$ across a magnetic $\mathrm{flux}$-containing superconductor when a sufficiently high current drives it into the flux-flow regime. Although the Josephson relation, $/ 1 / V=(h / 2 e) d \theta / d t$, where $\theta$ is the $\operatorname{diffe}-$ rence in the phase of the order parameter between two contacts, of ten has been used, $/ 2,4 /$ caution must be taken in using this expression, because the right-hand side depends upon the gauge chosen $/ 5 /$. The purpose of this paper is to derive a new properly gaugeinvariant expression, of the same form as the above equation but with a different interpretation, which should prove useful for calculations of the measured voltage $v$.

DERIVATION OF THE RESULT. - We consider the usual case of a superconducting specimen and a measuring circuit whose linear dimensions are all large by comparison with the field-dependent penetration depth $/ 6,7 / \lambda_{B}$. Inside the superconductor, the 1ocal flux density contribution $\vec{b}_{i}$ from vortex $i$ is large only within about $\lambda_{B}$ of the vortex axis or the surface. As sketched in figure 1, the associated magnetic flux $\phi_{0}=\mathrm{hc} / 2 \mathrm{e}$, which flows up through the specimen's interior, returns around the specimen's edges through the surrounding space. When the vortex moves, carrying its flux density contribution $\vec{b}_{i}$ with $i t$, the corresponding voltage contribution $V$ measured across terminals $A$ and $B$ of a sensitive voltmeter connected by leads $C_{M}$ to contacts a and $b$ is, to good approximation $/ 2,8 /$,

$$
\mathrm{v}=\mathrm{v}_{\mathrm{A}}-\mathrm{v}_{\mathrm{B}}=-\mathrm{c}^{-1} \mathrm{~d} \phi_{\mathrm{MS}} / \mathrm{d} \mathrm{t} \text {. }
$$

Here, $\phi_{M S}=\int d S \vec{b}_{i} \cdot \hat{n}$ is carried out over the surface $S_{M S}$ bounded by the contours $C_{M}$ and $C_{S}$. The contour $\mathrm{C}_{S}$ must be chosen to penetrate perpendiculary into the specimen and then to remain several $\lambda_{B}$ from the surface as it passes between $a$ and $b$ as shown in figure 1.

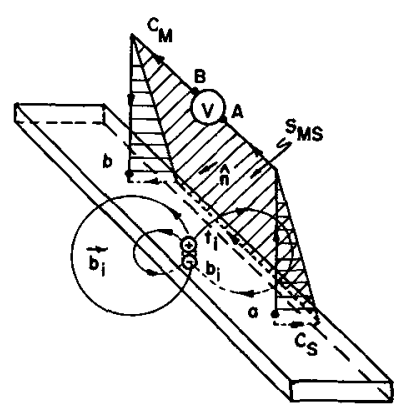

Fig. 1 : Sketch of measuring circuit and vortex $i$.

We next consider the self field $\vec{b}_{M}$ proceded by a virtual current $I_{M}$ through the measuring circuit, taking into account the Meissner effect, as indicated in figure 2. Large values of $\vec{b}_{M}$ are confined to the region outside the specimen and within $\lambda_{B}$ of the surface.

We now consider the integral of the field energy density $b^{2} / 8 \pi$, where $\vec{b}=\vec{b}_{i}+\vec{b}_{M}$. The interaction energy between vortex $i$ and the virtual current $I_{M}$ is $U_{\text {int }}=\int d^{3} r \vec{b}_{i} \cdot \vec{b}_{M} / 4 \pi$. We take the integral on $1 y$ over the space outside both the specimen and the leads and ignore the remaining contributions. We express $\vec{b}_{i}$ and $\vec{b}_{M}$ in terms of magnetic potentials via $\vec{b}_{i}=-\nabla \phi_{i}$ and $\vec{b}_{M}=-\nabla \phi_{M}$ and then evaluate $U_{i n t}$ in two ways. First, by using the identity $\nabla \phi_{i} \cdot \nabla \phi_{M}=$ $\nabla \cdot\left(\phi_{i} \nabla \phi_{M}\right)$ and applying the divergence theorem, we find that $U_{\text {int }}=0$, because $\vec{b}_{M}=-\nabla \phi_{M}$ is paralle1 to the specimen surface.

Next we use the indentity $\nabla \phi_{i} \cdot \nabla \phi_{M}=\nabla \cdot\left(\phi_{M} \nabla \phi_{i}\right)$ and again apply the divergence theorem to express $U_{\text {int }}$ 
in terms of integrals over the surfaces shown in figure 3 : the lead surfaces, the specimen surface $\mathrm{s}_{\mathrm{S}}$ and socalled cut surfaces $S_{c_{1}}$ and $S_{c_{2}}$, which are necessary to account for the fact that $\phi_{M}$ changes by $-4 \pi I_{M} / c$ in executing a circuit in the righthand sense around the lead.

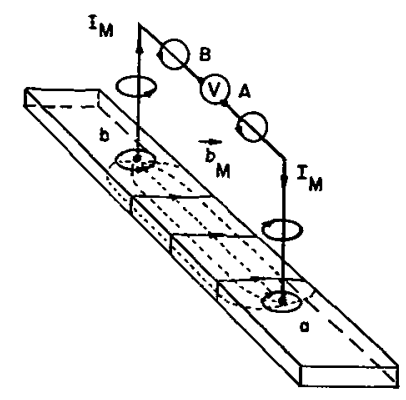

Fig. 2 : Sketch showing flux density $\vec{b}_{M}$ produced by virtual current $\mathrm{I}_{M}$.

The result is

$$
\mathrm{U}_{\text {int }}=\int \mathrm{dS}_{\mathrm{s}} \overrightarrow{\mathrm{b}}_{\mathrm{i}} \cdot \hat{\mathrm{n}}_{\mathrm{s}} \phi_{\mathrm{M}} / 4 \pi+\mathrm{I}_{\mathrm{M}} \phi_{\mathrm{c}} / \mathrm{c}=0,
$$

where $\phi_{c}=\phi_{\mathcal{C}_{1}}+\phi_{c_{2}}=-\phi_{M S}$ and $\phi_{c j}=\int d S_{c j} \vec{b}_{i} \cdot \hat{n}_{c j}$. Note also that $\vec{b}_{i} \cdot \hat{n}_{s}=0$, except very close to the top $t_{i}$ or the bottom $b_{i}$ of vortex $i$, where the surface integral of $\vec{b}_{i} \cdot \hat{n}_{s}$ is $\phi_{0}$ or $-\phi_{0}$, respectively.

From eqs. (1) and (2) we then obtain

$$
\mathrm{V}=(K / 2 \mathrm{e}) \mathrm{d} \theta / \mathrm{dt} \text {, }
$$

provided we define

$$
\theta=\left(c / 2 I_{M}\right) \int_{b_{i}}^{t} d \vec{r} \cdot \vec{b}_{M},
$$

where the line integral is taken over the path $C$ shown in figure 3 .

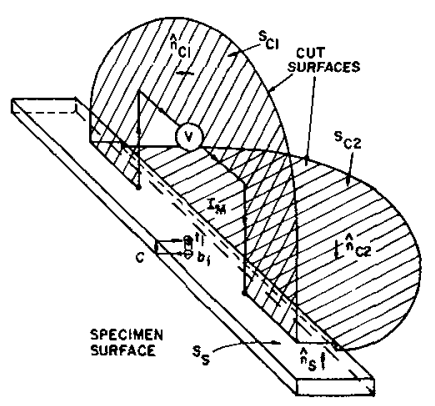

Fig. 3 : Sketch showing integration surfaces.

Note that $\theta=0$ when the vortex first enters the left side of the specimen and, by Ampere's law, that $\theta=2 \pi$ when it exits at the right side, provided it passes between $a$ and $b$. Thus $\theta$ can be regarded as the gaugeinvariant phase difference of the order parameter of vortex $i$ between the points $a$ and $b$. Note, however, that $\theta$ depends not only upon the relative positions of the top and bottom of vortex $i$ and the contacts $\mathrm{a}$ and $\mathrm{b}$, but a1so upon the shape of the specimen and the spatial configuration of the measuring circuit leads as they rise from $a$ and $b$ up to the voltmeter terminals $A$ and $B$.

The above treatment is easily applied to the case of a moving flux tube of flux $\phi=N \phi_{0}$ in a type-I superconductor, the result being the same as eq. (3) except that the right-hand side then includes an extra factor $\mathrm{N}$.

ACKNOWLEDGEMENT.- This work was supported by the U.S. Department of Energy, Division of Basic Energy Sciences.

\section{References}

/1/ Josephson, B.D., Advan. Phys. Phys. 14 (1965) 419.

/2/ Clem, J.R., Phys. Rev. B 1 (1970) 2140.

/3/ Burgess, R.E., Physica 55 (1971) 369.

14/ Choe, H.M. and Van Der Ziel, A., Physica $81 \mathrm{~B}$ (1976) 237.

/5/ De Gennes, P.G., Superconductivity of Metals and Alloys (W.A. Benjamin, Inc., New York, 1962), Chap. 5, P. 145.

16/ Clem, J.R., Low Temperature Physics - LT14, Vo1. 2, ed. by M. Krusius and M. Vuorio (NorthHoll and, Amsterdam, 1975), p. 285.

17/ Brandt, E.H., J. Low Temp. Phys. 26 (1977) 709.

/8/ Park, J.G., J. Phys.F : Meta1 Phys. 2(1972) 957. 